\title{
Evaluasi Aplikasi Penghalang Bunyi di Lingkungan Sekolah dalam Tinjauan Persepsi dan Ekonomi
}

\section{Evaluation of Sound Barrier Application in School Environment with Perception and Economic Review}

\author{
Muhamad Yusup Hidayat, Ridwan Fauzi, Budi Purwanto, dan Melania Hanny Aryantie \\ Puslitbang Kualitas dan Laboratorium Lingkungan BLI-KLHK, Kawasan Puspiptek Gedung 210, \\ Tangerang Selatan, 021-7563114, 15314, e-mail: yusup.fairuz@gmail.com
}

Diterima 15 September 2020, direvisi 25 September 2020, disetujui 19 Oktober 2020

\begin{abstract}
ABSTRAK
Evaluasi Aplikasi Penghalang Bunyi di Lingkungan Sekolah Dalam Tinjauan Persepsi dan Ekonomi. Komunikasi yang efektif antara guru pengajar kepada siswa selaku peserta didik sering terganggu karena kebisingan. Salah satu cara pengendalian kebisingan adalah pengendalian medium perambatan kebisingan dengan sound barrier. Penerapan sound barrier di lingkungan sekolah memerlukan penilaian persepsi siswa dan guru serta analisis ekonomi terhadap bahan atau materialnya. Tujuan penelitian ini adalah mengetahui persepsi siswa dan guru serta menghitung nilai ekonomi alat penghalang bunyi (sound barrier) berdasarkan lama waktu pemanfaatan dan biaya produksi. Penelitian ini menggunakan pendekatan kuantitatif dan kualitatif yaitu mendeskripsikan hasil skoring yang dilakukan. Analisis persepsi dilakukan dengan menggunakan analisis Likert. Penyusutan dihitung dengan nilai depresiasi alat. Hasil penelitian menunjukkan bahwa pemasangan sound barrier cukup sesuai untuk diaplikasikan di lingkungan sekolah dan meningkatkan kenyamanan kegiatan belajar mengajar karena mengurangi kebisingan yang dihasilkan dari kendaraan. Bahan sound barrier yang diaplikasikan sudah tetap dan dapat diterima responden namun perlu perbaikan aksesoris untuk meningkatkan estetika. Secara nilai ekonomi, penggunaan material kayu kamper (Dryobalanops sp.) sebagai bahan baku sound barrier cukup efisien jika dibandingkan dengan material berbahan akrilik, karena material kayu tersebut mempunyai nilai penyusutan yang rendah. Persepsi responden terhadap performa alat sound barrier cukup puas dan dapat diterima sebagai alat insulasi kebisingan.
\end{abstract}

Kata kunci: Komunikasi, ekonomi, medium perambatan, penghalang bunyi.

\section{ABSTRACT}

Evaluation of Sound Barrier Application in School Environment with Perception and Economic Review. Effective communication between teachers and students is often disrupted by environmental noise. One method to control the noise is by using a sound barrier. Implementation of the school environment's sound barrier requires the assessment of students' and teachers' perceptions, and economic analysis of the materials applied. This study aims to determine the perceptions of students and teachers and calculate the economic value of sound barriers based on its depreciation value and production costs making. This research uses quantitative and qualitative approaches to describe the scoring results. Perception analysis was performed using a Likert analysis. The amount of depreciation expense is analyzed using the depreciation formula. In general, the installation of a sound barrier is effective in a school building as it reduces the noise of passing vehicles, but it needs improvement in aesthetics. In terms of economic value, the use of Kamper wood (Dryobalanops sp.) as the raw material for the sound barrier is sufficiently efficient with a relatively low depreciation value compared to acrylic of the raw material. Respondents are quite satisfied with the sound barrier, and it can be accepted as a tool for noise insulation.

Keywords: Communication, economic, propagation medium, sound barrier. 


\section{Pendahuluan}

Aktivitas belajar dan mengajar di lingkungan sekolah berlangsung ketika adanya komunikasi yang efektif antara pengajar kepada siswa selaku peserta didik. Komunikasi yang efektif terjadi ketika pengajar selaku sumber informasi dapat ditransmisikan kepada siswa selaku resipient informasi dan sangat bergantung kepada keterampilan seseorang dalam mengirim maupun menerima pesan (Wulan Sari, 2016). Komunikasi menitikberatkan pada komunikator dan komunikan dalam menyampaikan suatu pesan (Hermoyo, 2014). Dengan komunikasi akan terjadi proses mempengaruhi sikap, pandangan, atau perilaku seseorang dalam bentuk kegiatan membujuk dan mengajak, sehingga ia melakukan dengan kesadaran sendiri (Wisman, 2017). Faktor yang mempengaruhi komunikasi dibagi kedalam tiga, yaitu faktor pembicara, faktor pendengar, dan faktor lingkungan.

Faktor lingkungan yang mempengaruhi proses komunikasi yaitu adanya gangguan fisik (kebisingan ambien, distorsi temporal yang dapat berupa gema dan atau dengung) (Utami, 2015). Gangguan lingkungan yang diakibatkan oleh kebisingan di sekitar sekolah salah satunya bersumber dari kendaraan bermotor. Lokasi sekolah yang cukup strategis (dekat jalan raya utama), selain memiliki dampak yang positif terhadap kemudahan akses, juga memiliki dampak yang negatif kebisingan dari lalu lintas kendaraan. Seiring dengan bertambahnya jumlah kendaraan yang melintas, tingkat kebisingan juga akan meningkat. Kebisingan kendaraan akan berdampak terhadap kenyamanan pelaksanaan kegiatan belajar mengajar di lingkungan sekolah. Untuk itu perlu dilakukan pengendalian kebisingan sekolah.

Pengendalian kebisingan dapat dilakukan melalui tiga unsur penting, yakni sumber kebisingan, medium perambatan kebisingan, dan penerima kebisingan (gedung sekolah) (Aini et al., 2018). Dari ketiga unsur tersebut, mitigasi pada jalur penghantar merupakan yang paling efektif dan efisien. Huboyo and Sumiyati (2015), menyatakan bahwa mitigasi jalur perambatan akan meningkatkan nilai transmission loss. Hal senada juga disampaikan oleh Prihatiningsih and Rahmawati (2019) dan Ramadhan et al. (2017), bahwa media perambatan efektif dalam memitigasi kebisingan. Mitigasi bising pada jalur penghantar dapat dilakukan dengan cara membangun penghalang bunyi (sound barrier). Untuk itu dalam penerapan sound barrier yang dipasang di lingkungan sekolah perlu dilakukan penilaian persepsi siswa dan guru yang mengajar serta analisis ekonomi bahan atau material yang digunakan. Melalui persepsi ini dapat dilihat harapan seseorang terhadap sesuatu (Ong \& Pambudi, 2014; Yogiesti et al., 2010; Aini et al., 2018). Penilaian persepsi ini dilakukan untuk melihat apakah aplikasi sound barrier tersebut efisien dan efektif untuk diterapkan di lingkungan sekolah.

Berdasarkan Peraturan Menteri Lingkungan Hidup Nomor 7 Tahun 2014 Tentang Kerugian Lingkungan Hidup Akibat Pencemaran dan/ Atau Kerusakan Lingkungan Hidup, diketahui bahwa untuk menghitung kerugian ekonomi akibat kebisingan dari jalan raya dihitung berdasarkan nilai properti yang terdampak. Nilai kerugian akibat hal tersebut dihitung sebesar 0,64 persen dari nilai properti. Selain nilai tersebut, material untuk meminimalisir eksternalitas negatif berupa kebisingan dari suatu aktivitas anthropogenik merupakan barang yang mempunyai nilai secara ekonomi (Jackson et al., 2009; Solow 2018; Zhou et al., 2015). Nilai ekonomi tersebut bisa diukur berdasarkan lama waktu dari pemanfaatan barang tersebut dengan mempertimbangkan biaya produksinya (Venkatachalam, 2007; Zhou et al., 2015). Semakin lama waktu pemanfaatan barang, 
maka akan semakin ekonomis suatu barang. Tentunya hal tersebut tergantung dari biaya produksi barang tersebut.

Penelitian ini dilakukan untuk mengetahui persepsi siswa dan guru pengajar terhadap pemasangan sound barrier yang dipasang dilokasi sekolah serta menghitung nilai ekonomi alat penghalang bunyi berdasarkan lama waktu pemanfaatan dan biaya produksi pembuatan alatnya.

\section{Metodologi}

\section{1. Lokasi Penelitian}

Penelitian ini dilakukan dilakukan pada bulan September sampai dengan Oktober 2019. Responden yang menjadi target pengambilan sampel adalah siswasiswi dan guru pengajar di SMAN 2 Cibinong Sebanyak 110 sampel dari 786 responden. Analisis kuisioner dilakukan di Kantor Pusat Penelitian Kualitas dan Laboratorium Lingkungan (P3KLL), Serpong.

\section{2. Metode}

Penelitianinimenggunakanpendekatan kuantitatif dan kualitatif. Data primer yang dikumpulkan di dalam penelitian ini meliputi kusioner, sedangkan data sekunder meliputi harga bahan pembuatan sound barrier. Pengumpulan data primer dilakukan secara survei menggunakan kuisioner, sedangkan data sekunder digunakan untuk melengkapi data dan informasi yang diperlukan. Metode pengambilan sampel yang dilakukan menggunakan rumus Slovin.

$$
n=\frac{N}{1+N e^{2}}
$$

Keterangan:

$n$ : jumlah sampel responden

$\mathrm{N}$ : jumlah populasi responden

e : batas toleransi kesalahan (error tolerance)

\section{3. Analisis data}

\subsubsection{Persepsi}

Analisis persepsi dilakukan dengan menggunakan analisis Likert.
Cara menghitung skor dan persentase penggolongan skor penilaian adalah sebagai berikut:

(a) Cara Menghitung Skor

Skor $=$ frekuensi $\mathrm{x}$ bobot nilai

Jumlah Skor $=$ jumlah skor skala penilaian 1 sampai dengan 5

(b) Cara penghitungan presentase penggolongan skor penilaian

Penggolongan skor penilaian dilakukan berdasarkan skor ideal, dimana nilainya tergantung pada jumlah responden yang ingin dilihat. Misalnya jika dibandingkan dengan jumlah keseluruhan responden, maka:

Skor ideal (skor tertinggi) $=$ jumlah keseluruhan responden $\mathrm{x}$ bobot nilai tertinggi

Skor terendah $=$ jumlah keseluruhan responden $\mathrm{x}$ bobot nilai terendah

Sehingga persentase penggolongan skor penilaian adalah:

Jumlah skor x 100\%

Skor Ideal

Kriteria interpretasi skor berdasarkan persentase kelompok responden:

1. Angka $0-20=$ Sangat Tidak Nyaman/ Tidak Berkurang Sama Sekali/ Sanat Susah/ Tidak ada Hubungan/ Tidak Ada Keterkaitan

2. Angka $21-40=$ Kurang Nyaman/ Tidak berkurang/ Susah/ Kurang Nyaman/ Berdampak Sekali/ Sangat Butuh Dipasang

3. Angka $41-60=$ Biasa Saja/ Ragu-ragu/ Butuh

4. Angka $61-80=$ Nyaman/Sedikit Berkurang/ Mudah/ ada sedikit Berdampak/ Sedikit Butuh Dipasang

5. Angka 81- = Sangat Nyaman/ $100 \quad$ Sangat Berkurang/ Sangat Mudah Sekali/ Tidak Ada Efek Sama Sekali/ Tidak Butuh Sama Sekali. 


\subsection{Analisis Ekonomi}

Besarnya beban penyusutan dalam penelitian ini menggunakan rumus sebagai berikut (Campbell, 1951; Noland, 2011):.

$r=\frac{c-s}{n}$

Keterangan:

$r=$ beban depresiasi per periode/ tahun

$c=$ harga perolehan

$s=$ nilai sisa

$n=$ jumlah periode $/$ masa manfaat

\section{Hasil dan Pembahasan}

\section{1. Persepsi Terhadap Performa Peredaman Sound Barrier}

Persepsi responden terhadap sound barrier merupakan tingkat penerimaan responden terhadap pemasangan sound barrier yang ada di lingkungan sekolah dalam menginsulasi sumber bunyi yang dihasilkan oleh kendaraan yang melintas dan terdengar kedalam ruang kelas. Adanya sound barrier akan menginsulasi menghalangi perambatan bunyi yang dihasilkan dari sumber bunyi yang ditransmisikan menuju penerima penerima bunyi (Aini et al.,
2018). Penilaian persepsi responden terlihat dari proses pelibatan komponen kognitif (berpikir), afektif (emosional), interpretatif, dan evaluatif yang dioperasikan bersamaan terhadap beberapa hal yang berhubungan dengan panca indera yang mempengaruhi kenyamanan manusia (Setiarini, 2014).

Hasil pengolahan data menggunakan analisis Likert yang dilakukan terhadap pemasangan sound barrier dengan bahan kayu kamper (Dryobalanops spp.), diperoleh perspesi responden terhadap kenyamanan ruang belajar setelah ruangan terpasang dengan sound barrier terkategorikan nyaman. Suara bising yang berasal dari kendaraan bermotor (knalpot) dan suara indikator penyeberangan lalu lintas dengan adanya sound barrier terkategorikan sedikit berkurang. Kebisingan tersebut apabila tidak dikendalikan akan menimbulkan gangguan kesehatan psikologis antara lain gangguan kenyamanan, gangguan komunikasi dan gangguan konsentrasi (Resiana et al., 2015).

Penilaian responden terhadap sound barrier di ruangan kelas untuk dipasang dan direplikasi di tempat lain terkategorikan

Tabel 1. Persepsi Responden terhadap Performa Peredaman Sound Barrier

\begin{tabular}{|c|c|c|c|}
\hline No & Deskripsi & Skor & Kriteria \\
\hline 1 & $\begin{array}{l}\text { Apakah saudara merasa nyaman dari kebisingan yang bersumber dari luar } \\
\text { ruangan/ non Kendaraan bermotor (setelah ruangan terpasang dengan } \\
\text { penghalang kebisingan) }\end{array}$ & 66,31 & Nyaman \\
\hline 2 & $\begin{array}{l}\text { Apakah Suara kebisingan yang berasal dari kendaraan bermotor (Knalpot) } \\
\text { dapat berkurang dengan adanya penghalang kebisingan }\end{array}$ & 77,84 & $\begin{array}{l}\text { Sedikit } \\
\text { Berkurang }\end{array}$ \\
\hline 3 & $\begin{array}{l}\text { Apakah suara indikator penyeberangan lalu lintas dapat teredam dengan } \\
\text { adanya penghalang kebisingan }\end{array}$ & 65,05 & $\begin{array}{l}\text { Sedikit } \\
\text { Berkurang }\end{array}$ \\
\hline 4 & $\begin{array}{l}\text { Apakah menurut saudara penghalang kebisingan di ruangan kelas ini } \\
\text { mudah untuk dipasang dan direplikasi di tempat lain }\end{array}$ & 68,83 & Mudah \\
\hline 5 & $\begin{array}{l}\text { Apakah menurut Saudara Kegiatan Belajar Mengajar (KMB) Jauh lebih } \\
\text { nyaman setelah diterapkan barrier }\end{array}$ & 72,61 & Nyaman \\
\hline 6 & $\begin{array}{l}\text { Apakah ada efek terhadap suasana/ lingkungan sekolah/ kelas dengan } \\
\text { adanya pemasangan alat peredam kebisingan (misalkan : Signal WIFI } \\
\text { terhambat, Cahaya Menjadi redup/terang, dll) }\end{array}$ & 71,27 & Biasa Saja \\
\hline 7 & $\begin{array}{l}\text { Menurut Saudara apakah masih dibutuhkan pengeras suara bagi siswa di } \\
\text { kelas setelah dipasang alat penghalang kebisingan }\end{array}$ & 72,43 & $\begin{array}{l}\text { Sedikit } \\
\text { Butuh } \\
\text { Dipasang }\end{array}$ \\
\hline
\end{tabular}

Sumber: Hasil Pengolahan data primer, 2020 
mudah. Hal ini memperlihatkan alat sound barrier tidak memerlukan penyesuaian bentuk dan desain yang banyak apabila diaplikasi di tempat yang berbeda. Penilaian responden terhadap kegiatan belajar mengajar dengan adanya sound barrier ini terkategorikan nyaman. Tidak ada gangguan yang berarti setelah pemasangan sound barier terhadap sinyal WiFi terhambat, ataupun cahaya menjadi redup/terang. Hal yang perlu ditambahkan untuk menambah kenyamanan kegiatan belajar mengajar yaitu pemasangan alat pengeras suara di kelas, untuk membantu memperjelas kenyamanan pembelajaran di ruangan kelas.

Secara umum, penilaian responden dalam hal performa peredaman sound barrier cukup sesuai untuk diterapkan di lingkungan sekolah. Sound barrier memberikan nilai positif dalam meningkatkan kenyamanan kegiatan belajar mengajar, terutama terhadap peredaman kebisingan yang dihasilkan oleh kendaraan yang melintas di depan ruangan belajar mengajar. Bahan peredam kebisingan banyak menggunakan bahan kayu karena mempunyai nilai estetika dan lebih efisien. Selain itu, studi yang lain membuktikan bahwa bahan kayu mampu mengurangi kebisingan hingga 12,15\% (Septiana et al., 2015).

\section{2. Persepsi Responden Terhadap Estetika Bahan Sound Barrier}

Kualitas insulasi/penyekatan oleh sound barrier dalam mereduksi kebisingan lingkungan yang yang dihasilkan kendaraan bermotor antara lain dipengaruhi oleh kualitas bahan yang dipergunakan. Bahan yang digunakan sebagai sound barrier harus dapat mereduksi bising secara maksimal (Huboyo \& Sumiyati, 2015). Selain menentukan kualitas insulasi, kualitas bahan yang dipergunakan juga mempengaruhi estetika alat yang terpasang. Nilai estetika ini juga mempengaruhi kenyamanan dan tingkat penerimaan indra penglihatan responden. Secara rinci tingkat penerimaan dan penilaian responden terhadap kualitas alat dan bahan sound barrier tersaji pada tabel berikut:

Tabel 2. Persepsi Responden terhadap Estetika Bahan Sound Barrier

\begin{tabular}{|c|c|c|c|}
\hline No & Deskripsi & Skor & Kriteria \\
\hline 1 & $\begin{array}{l}\text { Apakah kayu kamper yang dipergunakan sebagai penghalang } \\
\text { kebisingan sudah tepat digunakan }\end{array}$ & 71,89 & Tepat \\
\hline 2 & $\begin{array}{l}\text { Apakah warna penghalang kebisingan yang paling cocok diaplikasikan } \\
\text { di ruangan sekolah }\end{array}$ & 72,97 & Warna Gelap \\
\hline 3 & $\begin{array}{l}\text { Apakah corak penghalang kebisingan yang paling cocok untuk } \\
\text { diaplikasikan di ruangan sekolah }\end{array}$ & 56,76 & Tidak Tahu \\
\hline 4 & $\begin{array}{l}\text { Apakah bentuk alat penghalang kebisingan yang dipasang mengganggu } \\
\text { keindahan/estetika ruangan }\end{array}$ & 35,50 & Tidak Tahu \\
\hline 5 & $\begin{array}{l}\text { Menurut Saudara, apakah lebih cocok menggunakan penghalang } \\
\text { kebisingan ataukan pembatas/ pagar yang tinggi untuk mengurangi } \\
\text { kebisingan di lingkungan Sekolah }\end{array}$ & 84,00 & $\begin{array}{l}\text { Penghalang } \\
\text { Kebisingan }\end{array}$ \\
\hline 6 & $\begin{array}{l}\text { Apakah menurut Saudara alat penghalang kebisingan yang dipasang } \\
\text { mudah untuk dilepas dan dirakit (Knock Down) }\end{array}$ & 62,14 & Tidak Tahu \\
\hline 7 & $\begin{array}{l}\text { Apakah perlu untuk ditambahkan aksesoris/ tambahan alat pada } \\
\text { penghalang kebisingan yang dipasang di ruangan Sekolah }\end{array}$ & 71,89 & $\begin{array}{l}\text { Perlu untuk } \\
\text { ditambahkan } \\
\text { aksesories }\end{array}$ \\
\hline 8 & $\begin{array}{l}\text { Menurut Saudara apakah perlu untuk penataan ulang tata letak dari } \\
\text { penghalang kebisingan yang telah dipasang }\end{array}$ & 57,12 & Tidak Tahu \\
\hline
\end{tabular}

Sumber : Hasil Pengolahan data primer, 2020 
Persepsi responden terhadap penggunaan bahan sound barrier dari kayu kamper (Dryobalanops spp.) menyatakan tepat. Responden menyatakan penggunaan kayu masih dirasa tepat untuk digunakan sebagai bahan insulator. Responden menyatakan, warna yang dirasa cocok untuk digunakan sebagai bahan insulator adalah berwarna gelap. Terkait dengan corak dan bentuk sound barrier yang diaplikasikan responden menyatakan tidak terlalu mempermasalahkan.

$$
\text { Sebagai insulator kebisingan, }
$$
responden menyatakan sound barrier lebih cocok diterapkan dibandingkan dengan pagar yang tinggi. Hal ini menunjukan sound barrier lebih tepat guna sebagai penghalang kebisingan dibandingkan dengan pagar yang tinggi. Dalam hal kemudahan untuk pemasangan dan perakitan, responden menyatakan sound barrier mudah untuk diaplikasikan di lingkungan sekolah, namun responden menyatakan perlu penambahan aksesoris untuk meningkatkan nilai estetika dan fungsi dari sound barrier. Secara tata letak, responden menyatakan sudah tepat meletakan alat sound barrier di pagar pembatas dengan jalan raya. Secara umum, estetika bahan sound barrier yang diaplikasikan sudah tepat dan dapat diterima oleh responden, namun perlu perbaikan dalam hal aksesoris untuk meningkatkan estetika, agar lebih terlihat indah tanpa mengurangi nilai fungsi dari alat tersebut. Meminimalkan dampak negatif terhadap lingkungan dapat dikemas dengan memperhatikan bentuk aksesoris yang memiliki nilai estetika, hal ini akan memberi nilai tambah terhadap material yang digunakan (Kusumoarto \& Librianti, 2018; Marliani, 2014).

\subsection{Analisis Ekonomi Penggunaan Sound Barrier di SMAN 2 Cibinong}

Bahan sound barrier yang diujicobakan dalam penelitian adalah berbahan kayu kamper (Dryobalanops sp.). Kajian ini menggunakan pembanding dengan berbahan akrilik. Umur ekonomis alat peredam dengan menggunakan akrilik hingga 30 tahun (Evonik Industries, 2019). Berdasarkan pengumpulan data dan perhitungan biaya pembuatan alat peredam kebisingan dengan menggunakan bahan baku akrilik mencapai Rp.3.796.000,- setiap meter persegi (Tabel 3).

Bahan sound barrier dengan kayu kamper mempunyai nilai tambah dari sisi estetika dan bahan ramah lingkungan.

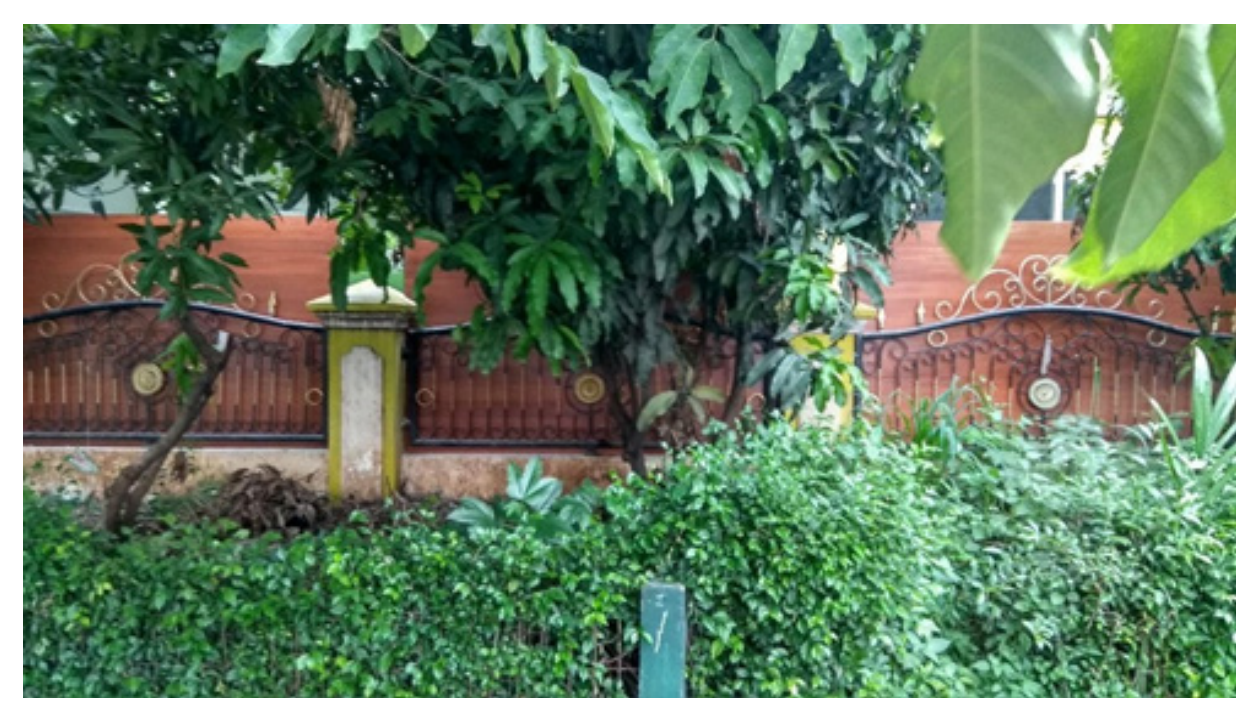

Sumber: Dokumentasi Pribadi (2018)

Gambar 1. Alat Peredam Kebisingan (Sound Barrier) yang Terpasang di Pagar Sekolah 
Tabel 3. Rincian Bahan Pembuatan Sound Barrier dari Akrilik

\begin{tabular}{llccrr}
\hline No. & Uraian & Volume & Satuan & Harga Satuan & Jumlah \\
\hline 1 & Baut 12mm & 20 & Buah & 5.000 & 100.000 \\
2 & Besi Siku & 1 & Batang & 90.000 & 90.000 \\
3 & Cat besi & 1 & Kaleng & 50.000 & 50.000 \\
4 & Kuas & 1 & Buah & 10.000 & 10.000 \\
5 & Beton K250 & 1 & $\mathrm{~m}^{3}$ & 840.000 & 840.000 \\
6 & Besi kerangka & 1 & Paket & 400.000 & 400.000 \\
7 & Cakar ayam & 2 & Buah & 110.000 & 220.000 \\
8 & Bahan Acrylic $15 \mathrm{~mm}$ & 1 & $\mathrm{~m}^{2}$ & 1.700 .000 & 1.700 .000 \\
9 & Baut Dynabolt & 8 & Buah & 12.000 & 96.000 \\
10 & Biaya pasang & 1 & Unit & 40.000 & 40.000 \\
11 & Biaya pembuatan & 1 & Unit & 250.000 & 250.000 \\
\hline & & Total & & 3.796 .000 \\
\hline
\end{tabular}

Sumber : Hasil Pengolahan data primer, 2020

Tabel 4. Rincian Bahan Pembuatan Sound Barrier Dari Kayu Kamper

\begin{tabular}{clccrr}
\hline No. & \multicolumn{1}{c}{ Uraian } & Volume & Satuan & Harga Satuan & \multicolumn{1}{c}{ Jumlah } \\
\hline 1 & Baut Dynabolt & 4 & Buah & 12.000 & 48.000 \\
2 & Besi Siku & 2 & Batang & 90.000 & 180.000 \\
3 & Pelitur kayu & 1 & Kaleng & 16.000 & 16.000 \\
4 & Kuas & 1 & Buah & 10.000 & 10.000 \\
5 & Semen & 2 & Kg & 5.000 & 10.000 \\
6 & Bahan kayu kamper & 1 & $\mathrm{~m}^{2}$ & 540.000 & 540.000 \\
7 & Biaya pasang & 1 & Unit & 40.000 & 40.000 \\
8 & Biaya pembuatan & 1 & Unit & 250.000 & 250.000 \\
\hline & & Total & & & 1.094 .000 \\
\hline
\end{tabular}

Sumber: Hasil Pengolahan data primer, 2020

Berdasarkan sisi kualitas kayu, kayu kamper tergolong dalam kelas awet I s.d. III, yang didasarkan pada lama pemakaian pada kondisi terpengaruh cuaca namun tidak terendam air dan tidak kekurangan udara dapat tahan 10 - 20 tahun (Danu et al., 2006; Martawijaya et al., 2005). Umur ekonomis kayu kamper sebagai sound barrier 10 hingga 20 tahun. Kayu kamper selain memiliki kelas awet I s.d. III juga mempunyai kelas kuat II s.d. IV (Martawijaya et al., 2005). Berdasarkan pengumpulan data dan perhitungan biaya diperoleh jumlah biaya yang dibutuhkan untuk membuat sound barrier menggunakan bahan baku kayu kamper mencapai Rp1.094.000,00 setiap meter persegi (Tabel 4). Biaya pembuatan sound barrier menggunakan bahan kayu kamper lebih murah dibandingkan dengan menggunakan bahan akrilik. 
Tabel 5. Efisiensi Penggunaan Material Sebagai Alat Peredam Kebisingan

\begin{tabular}{llccc}
\hline No. & Bahan & $\begin{array}{c}\text { Biaya per meter } \\
\text { (rupiah) }\end{array}$ & $\begin{array}{c}\text { Umur ekonomis } \\
\text { (tahun) }\end{array}$ & $\begin{array}{c}\text { Penyusutan per Tahun } \\
\text { (rupiah) }\end{array}$ \\
\hline 1 & Akrilik & 3.796 .000 & 30 & $126.533,33$ \\
2 & Kayu Kamper & 1.094 .000 & 20 & $54.700,00$ \\
\hline
\end{tabular}

Sumber: Hasil Pengolahan data primer, 2020

Ada tiga hal yang perlu diketahui dalam menghitung penyusutan alat, yaitu harga perolehan, nilai residu (akhir), dan umur ekonomis alat (Jading et al., 2015). Perhitungan nilai penyusutan dalam kajian ini menggunakan metode garis lurus. Metode tersebut, beban penyusutan peralatan akan memiliki nilai yang sama besar di setiap tahun penggunaan/ pemanfaatan. Jika dituangkan dalam grafik nilai beban penyusutan dapat digambarkan dengan garis lurus.

Berdasarkan perhitungan dengan menggunakan persamaan 1 diperoleh nilai penyusutan per tahun Rp.126.533,33 dengan menggunakan bahan baku akrilik. Sementara itu, dengan menggunakan bahan baku kayu kamper diperoleh nilai penyusutan per tahun sebesar Rp.54.700,00. Nilai penyusutan penggunaan kayu kamper yang lebih rendah membuktikan bahwa secara ekonomi penggunaan material kayu kamper lebih efisien dan murah sebagai bahan baku sound barrier. Jika dianalogikan dalam suatu usaha nilai penyusutan yang rendah akan mempengaruhi investor dalam melakukan investasi. Semakin rendah nilai penyusutan maka akan semakin tinggi nilai ekonomi yang didapatkan dalam investasi tersebut (Ackermann \& Fochmann, 2016).

\section{Simpulan}

\section{1. Kesimpulan}

Persepsi responden terhadap performa alat penghalang bunyi (sound barrier) cukup puas dan dapat diterima sebagai alat insulasi kebisingan yang bersumber dari kendaran bermotor yang melintas di depan ruangan kelas. Responden merasa kegiatan belajar mengajar menjadi lebih nyaman setelah pemasangan sound barrier. Penggunaan kayu kamper sebagai bahan sound barrier sudah cukup sesuai, namun perlu peningkatan estetika melalui penambahan aksesories untuk meningkatkan nilai keindahan alat. Secara ekonomi penggunaan material kayu kamper lebih efisien dan murah sebagai bahan baku alat sound barrier bila dibandingkan dengan bahan akrilik.

\subsection{Saran}

Perlu mempertimbangkan penelitian lanjutan pernggunaan material kayu yang memiliki kualitas setara atau bahkan lebih baik namun memiliki nilai ekonomis yang lebih baik dari kayu Kamper agar dapat diproduksi secara masal namun memiliki nilai harga yang ekonomis.

\section{Ucapan Terima Kasih}

Ucapan terimakasih disampaikan kepada Pusat Penelitian dan Pengembangan Kualitas dan Laboratorium Lingkungan atas bantuan dalam pembiayaan dan kelancaran pelaksanaan penelitian ini serta SMAN 2 Cibinong yang telah memfasilitasi dalam kelancaran selama pengumpulan data kuisioner penelitian.

\section{Kepengarangan}

Muhamad Yusup Hidayat berkontribusi dalam melakukan mengolahan data persepsi responden terhadap aplikasi sound barrier dan persepsi responden terhadap bahan sound barrier yang dipergunakan, 
serta mendeskripsikan hasil analisis yang dilakukan. Ridwan Fauzi berkontribusi di dalam melakukan analisis ekonomi aplikasi sound barrier di lingkungan Sekolah. Budi Purwanto berkontribusi dalam hal penyusunan pendahuluan naskah serta uraian teknis terkait dengan aplikasi sound barrier. Sedangkan Melania Hanny Aryantie berkontribusi dalam hal penyusunan kuisioner persepsi responden terhadap aplikasi sound barrier dan merekap data hasil pengumpulan kuisioner.

\section{Daftar Pustaka}

Ackermann, H., \& Fochmann, M. (2016). The effect of straight-line and accelerated depreciation rules on risky investment decisions-An experimental study. International Journal of Financial Studies, 4(4), 19. doi://10.3390/ijfs4040019.

Aini, A. N., Anwar, I. F., Sufanir, A. M. S., \& Astor, Y. (2018). Survei dan pemetaan zona kebisingan arus lalu lintas pada kawasan RSUP DR Hasan Sadikin Bandung. Jurnal Sipil Politikenik, 20(6), 2-6.

Campbell, J. D. (1951). Straight-line method of depreciation. Accounting Review, 26(1), 40-42.

Danu, S., Darsono, \& Sunarni, A. (2006). Pelapisan permukaan kayu lapis dengan polimer akrilat menggunakan radiasi ultra violet. Indonesian Journal of Materials Science, 7(3), 45-51.

Evonik Industries. (2019). Guarantee Statement: PLEXIGLAS ${ }^{\circledR}$ - 30 Year Guarantee. Evonik Röhm GmbH, 2626505.

Hermoyo, R. P. (2014). Anak usia dini. Jurnal Pedagogi, 1(Agustus), 1-22.

Huboyo, H. S., \& Sumiyati, S. (2015). Pengendalian kebisingan dengan penghalang bising dan variasi bahan peredam pada proses produksi di unit laundry PT Sandang Asia Maju Abadi. Jurnal Teknik Lingkungan, 4, 1-10.

Jackson, S. B., (Kelvin) Liu, X., \& Cecchini, M. (2009). Economic consequences of firms' depreciation method choice:
Evidence from capital investments. Journal of Accounting and Economics. doi://10.1016/j.jacceco.2009.06.001.

Jading, A., Payung, P., \& Reniana, R. (2015). Kajian teknis-ekonomis alat pengering pati sagu model cross flow vibro fluidized bed. Jurnal Agritech, 34(04), 448. doi://10.22146/agritech.9440.

Kusumoarto, A., \& Librianti, D. (2018). Desain taman lingkungan permukiman di Kota Bogor berbasis aktivitas komunitas. Seminar Nasional dan Diskusi Panel Multidisiplin Hasil Penelitian \& Pengabdian Kepada Masyarakat, 99-108.

Marliani, N. (2014). Pemanfaatan limbah rumah tangga ( sampah anorganik) sebagai bentuk implementasi. Formatif, 4(2), 124-132.

Martawijaya, A., Kartasujana, I., Kadir, K., \& Prawira, S. A. (2005). Atlas Kayu Indonesia (Indonesian Wood Atlas). In Atlas Kayu Indonesia.

Noland, T. R. (2011). The sum-of-years' digits depreciation method: use by SEC filers. Journal of Finance and Accountancy, 5, $1-12$.

Ong, J. O., \& Pambudi, J. (2014). Analisis kepuasan pelanggan dengan importance performance analsis di SBU laboratory Cibitung PT SUCOFINDO (Persero). Jati Undip, IX(1), 1-10.

Prihatiningsih, D., \& Rahmawati, S. (2019). Noise Level mapping in settlements around the railroad tracks Gondokusuman SubDistrict.

Ramadhan, A., Nugrahayu, Q., \& Azmi, A. (2017). Pemanfaatan busa sebagai media peredam kebisingan untuk ruang perpustakaan di sekolah dasar negeri Widoro Kota Yogyakarta.

Resiana, F., Lubis, M. S., \& Siahaan, S. (2015). Efektivitas penghalang vegetasi sebagai peredam kebisingan lalu lintas di kawasan pendidikan Jalan Ahmad Yani Pontianak. Jurnal Teknologi Lingkungan Lahan Basah, 3(1), 1-10. doi://10.26418/jtllb. v3i1.9290.

Septiana, S., Erwin, \& Defrianto. (2015). Analisa pengaruh keberadaan bangunan terhadap tingkat kebisingan di sepanjang Jalan Raya Pekanbaru-Bangkinang. JOM 
FMIPA, 2(1), 41-48. doi://10.1088/17518113/44/8/085201.

Setiarini, V. (2014). Studi deskriptif mengenai persepsi tentang kenyamanan lingkungan di sekitar pabrik pengolahan batu pada masyarakat karst Citatah.

Solow, R. M. (2018). The economics of resources or the resources of economics. In Discounting and Environmental Policy. doi://10.4324/9781315199818-17.

Utami, P. W. (2015). Faktor-faktor yang mempengaruhi komunikasi interpersonal guru dan siwa kelas IIIB SDIT Luqman AlHakim internasional, Banguntapan, Bantul, Yogyakarta. In Universitas Negeri Yogyakarta.

Venkatachalam, L. (2007). Environmental economics and ecological economics: Where they can converge? Ecological Economics. doi://10.1016/j. ecolecon.2006.05.012.
Wisman, Y. (2017). Komunikasi efektif dalam dunia pendidikan. Jurnal Nomosleca, 3(2), 646-654. doi://10.26905/nomosleca. v3i2.2039.

Wulan Sari, A. (2016). Pentingnya ketrampilan mendengar dalam menciptakan komunikasi yang efektif. edutech: Jurnal Ilmu Pendidikan dan Ilmu Sosial, 2(1), 1-10.

Yogiesti, V., Hariyani, S., \& Sutikno, F. R. (2010). Pengelolaan sampah terpadu berbasis masyarakat kota KEDIRI. Tata Kota dan Daerah, 2(2), 95-102.

Zhou, S., Huang, Y., Yu, B., \& Wang, G. (2015). Effects of human activities on the ecoenvironment in the middle Heihe River Basin based on an extended environmental Kuznets curve model. Ecological Engineering, 76, 14-26. doi://10.1016/j. ecoleng.2014.04.020. 